\title{
A rare complication of a malleable penile prosthesis: migration to the thigh region
}

\author{
Ercan Ogreden ${ }^{1}$, Bayram Güner ${ }^{1}$ and Erdal Benli ${ }^{2}$ \\ Asian Journal of Andrology (2013) 15, 852-853; doi:10.1038/aja.2013.107; published online 9 September 2013
}

Dear editor,

Here, we discuss an unusual prosthesis migration to the thigh region. Because the incidence of erectile dysfunction increases in parallel with the prevalence of neurological, degenerative and vascular diseases among elderly men, the use of penile prostheses is common in this age group. Still, cylinder migration following the implantation of a malleable penile prosthesis is a very rare entity.

A 47-year-old male patient was admitted to our clinic after the sudden loss of penile rigidity 6 months earlier and because of pain radiating from his right groin to the rectal region and the beginnings of tenesmus. He had undergone the implantation of a penile prosthesis only onto his right corpus cavernosum secondary to a penile fracture. The patient had no comorbid diseases, and his physical examination and blood work were normal. Skin erosion secondary to the pressure from the prosthesis was present inferior to the femoral triangle and medial to the anterior thigh in the right groin region, and a hard object was palpated. The other edge of the prosthesis was angled towards the rectal region. After X-rays had been taken, a 14-15 cm-length radioopaque material was detected to have one edge pointed towards the right femoral corpus and the other, towards the rectum (Figure 1). A tubular operation material with a thickness of $1 \mathrm{~cm}$ started from the area lateral to the anal canal under the skin and followed a path through a long segment ending at the medial thigh region, according to superficial tissue ultrasonography. His urine culture was sterile, and his laboratory tests were normal. No fistula formations were found. The migrated prosthesis was removed under spinal anaesthesia with the help of a clamp and a dissector via an incision in the region of the medial thigh. The location of the prosthesis was irrigated with a dilute povidone iodine and gentamicin solution after the extraction of the prosthesis. No complications were observed perioperatively. The patient was discharged on postoperative day 1 with oral antibiotherapy. He had no complications at the first week, first month or third month follow-ups after the operation.

Many complications have been reported in the literature regarding penile prostheses. The migration of the prosthesis or portions of it are observed very rarely and occur only in a few cases receiving inflatable prosthetic implants. A case of cylinder migration was reported by Abdulmuttalip et al., ${ }^{1}$ where one of the cylinders was ultimately removed due to migration. Although the migration of inflatable penile prostheses to the bladder, small bowels, urinary diversion, distal ureter and scrotum has been reported, to our knowledge, the migration of a malleable penile prosthesis to the thigh area is unique in the literature. $^{2-5}$ Possible reasons for this cylinder migration were damage to the corpus cavernosum during use or perioperatively and improper fixation of the cylinder.

We believe that more detailed information should be given to these patients about the possible long-term complications that can occur after the implantation of the prosthesis, stressing the importance of early treatment and regular follow-up exams, the latter of which patients sometimes avoid due to possible social traditions and embarrassment. Patients often neglect to consult a physician earlier because of social traditions or feelings of shame.

The data in the literature provide us with partial information on reservoir migration; however, it is difficult to estimate how a malleable penile prosthesis should behave. In this case, we believe that patients should be informed about the potential for migration, causing the prosthesis to press on the rectum and cause serious comorbidities by compressing the femoral vessel and nerve complex.

In the present case, the cylinder fixation was not evident immediately after the first operation. Preoperatively, we did not discover the route of the implant's migration or whether it had migrated from the tip or the crus. However, although the prosthesis had not completely extruded from the skin, it arrived near the skin via the subcutaneous tract between the proximal crus of the penis and the anteromedial thigh region. The centre where the operation had been performed was in another country, so we never learned why only one cylinder was implanted. We believe that the surgeon was not well trained and that most likely, a corporeal laceration had occurred during the operation and cylinder fixation had not been achieved.

Penoscrotal and scrotal approaches are preferred more often in surgical treatment, although different incisions can be used for extraordinary conditions. Still, we prefer to make skin incisions in the hope of preventing possible rectal complications and infections. It would be more logical to approach the treatment of such cases of migrated penile prostheses individually by considering the patient's expectations. At present, the incision was made through the anterior thigh region, which had the shortest possible skin tract, because the material of the prosthesis material had almost reached the subcutaneous space and thinned the skin. The patient definitively did not desire a further prosthesis implantation, and no complications were observed perioperatively.

${ }^{1}$ Department of Urology, Giresun Ada Hospital, Giresun 28100, Turkey and ${ }^{2}$ Department of Urology, Ordu University, Ordu 52000, Turkey Correspondence: Dr E Ogreden (9isik061@mynet.com)

Received: 1 June 2013; Revised: 28 June 2013; Accepted: 19 July 2013; Published online: 9 September 2013 


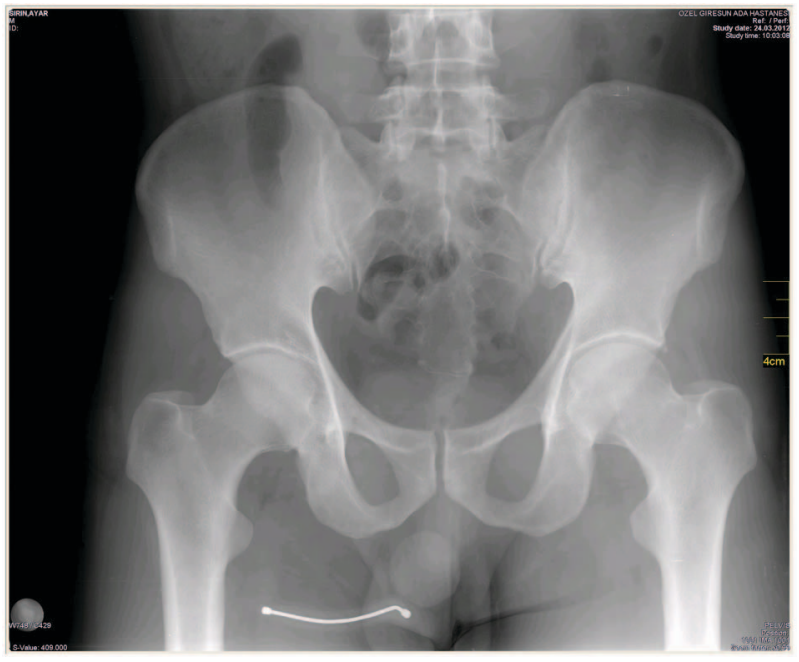

Figure 1 One of malleable penile prosthesis cylinders is shown as migrated on $\mathrm{X}$ ray graph.

Patients should be informed about possible complications due to penile prostheses, which can arise in either the acute or chronic period after the implantation of the prosthesis. Surgical revision is necessary in cases of migration and should be planned individually, according to the desires of each particular patient.

\section{AUTHOR CONTRIBUTIONS}

$B G$ acquired the data and performed the analysis and interpretation of the data. EB participated in the design of the study. EO and BG conceived the study, participated in its design and coordination and helped to draft the manuscript. All authors read and approved the final manuscript.

\section{COMPETING FINANICAL INTEREST}

All authors declare that there are no competing financial interests.

1 Simsek A, Kurt O, Ozbek E, İlbey YO, Ozcan L et al. Penil protez implantasyonu otuz olgunun gözden geçirilmesi. Kartal Res Trai Hosp Med J 2009; 20: 130-3.

2 Minervini A, Ralph DJ, Pryor JP. Outcome of penile prosthesis implantation for treating erectile dysfunction: experience with 504 procedures. BJU Int 2006; 97 129-33.

3 Nukui F, Okamoto S, Nagata M, Kurokawa J, Fukui J. Complications and reimplantation of penile implants. Int J Urol 1997; 4: 52-4.

4 Mould JW, Carson CC. Infectious complications of penile prostheses. Infect Urol 1989; 139: 50-2.

5 Leach GE, Shapiro CE, Hadley R, Raz S. Erosion of inflatable penile prosthesis reservoir into bladder and bowel. J Urol 1984; 131: 1177-8. 